\title{
The Effect of Atrial Fibrillation on Inpatient Outcomes of Patients with Acute Pancreatitis: A Two-year National Inpatient Sample Database Study
}

\author{
${ }^{1}$ Department of Internal Medicine, St. Mary's of Michigan, Saginaw, MI, USA \\ ${ }^{2}$ Central Michigan University College of Medicine, Saginaw, MI, USA \\ ${ }^{3}$ John H. Stroger Hospital of Cook County, Chicago, IL, USA \\ ${ }^{4}$ Medical College of Wisconsin Affiliated Hospitals, Milwaukee, WI, USA \\ ${ }^{5}$ Department of Gastroenterology, Cleveland Clinic Florida, Weston, FL, USA \\ ${ }^{6}$ McLaren Greater Lansing Hospital, Lansing, MI, USA
}

SHAKEEL JAMAL, MD, ${ }^{1,2}$ MUHAMMAD ZATMAR KHAN, MD, ${ }^{1,2}$ ASIM KICHLOO, MD, ${ }^{1,2}$ EHIZOGIE EDIGIN, MD, ${ }^{3}$ BETH BAILEY, PhD, ${ }^{2}$ MICHAEL ALJADAH, MD, ${ }^{4}$ ISHTIAQ HUSSAIAN, MD, ${ }^{5}$ ASAD UR RAHMAN, MD, ${ }^{5}$ MUHAMMAD AHMAD, MD, ${ }^{2}$ and KHALIL KANJWAL, $\mathrm{MD}^{6}$
ISSN 2156-3977 (print) ISSN 2156-3993 (online) CC BY 4.0 license

(C) 2020 Innovations in Cardiac Rhythm Management

KEYWORDS. Atrial fibrillation, National Inpatient Sample, pancreatitis, outcomes.

\section{Introduction}

Acute pancreatitis is an inflammatory condition involving the pancreatic and/or peripancreatic tissues. It can lead to systemic inflammatory response syndrome
(SIRS) and, if severe, can result in multiorgan failure. ${ }^{1-6}$ Mortality in acute pancreatitis can occur in two waves: an early wave due to underlying SIRS and multiorgan dysfunction syndrome (MODS) and a late wave attributed 
to MODS combined with sepsis caused by pancreatic tissue necrosis due to infection. ${ }^{7}$ Survival is determined by the early development of SIRS and the persistence of MODS. ${ }^{8}$

When MODS occurs, the cardiovascular system may be affected, which results in cardiac rhythm and contractility disturbances as well as peripheral vasomotor dysfunction. Changes in cardiac physiology have been reported at the histological level, with myofiber edema and disruption of the intercellular junctions. ${ }^{4,5}$ These changes at the cellular level can result in hemodynamic, cardiac conduction, and pericardial abnormalities.

Acute pancreatitis has an incidence ranging from five to 80 per 100,000 people. ${ }^{6}$ Acute pancreatitis is the most common cause of gastrointestinal-related hospital admission. ${ }^{8}$ The mortality of hospitalized patients with acute pancreatitis is $5 \%$ to $10 \%$ and up to $30 \%$ in severe cases. ${ }^{9,10}$ Several different scoring systems have been developed to predict in-hospital mortality in acute pancreatitis based on several clinical variables. Studies have reported an association of acute pancreatitis with atrial fibrillation (AF) and flutter that resolves after treatment of acute pancreatitis. ${ }^{11}$ We hypothesized that AF may worsen the clinical outcomes in patients with acute pancreatitis and that good control of AF may improve patient outcomes. To further evaluate our hypothesis, we conducted a cross-sectional analysis.

\section{Methods}

\section{Data source}

The NIS has been elaborated on in detail in a prior study. ${ }^{12}$ Briefly, it is the largest publicly available database in the United States that falls under the purview of the Healthcare Cost and Utilization project and is maintained by the Agency for Healthcare Research and Quality. It is one of the most useful databases used to assess outcomes and trends of various procedures and diseases and includes de-identified data collected from $20 \%$ of community hospitals in 46 states. Each hospitalization is representative of one primary diagnosis, up to $29 \mathrm{sec}-$ ondary diagnoses, and 15 procedures using International Classification of Diseases (ICD), ninth revision, clinical modification $(\mathrm{CM})$ or ICD, $10^{\text {th }}$ revision (ICD-10)-CM codes. The data include admission status, demographics, admitting diagnosis, comorbidities, location of healthcare facility (rural or urban), discharge diagnosis, outcomes, length of stay, and cost during hospitalization. We examined all adult patients who were hospitalized in the United States in 2016 and 2017 with the diagnosis of acute

Dr. Kanjwal is a consultant for Abbott Laboratories, St. Jude Medical, Johnson \& Johnson, and Biosense Webster. The other authors report no conflicts of interest for the published content.

Manuscript received July 26, 2020. Final version accepted August 20, 2020.

Address correspondence to: Michael Aljadah, MD, 8701 Watertown Plank Road, Milwaukee, WI 53226, USA. Email: maljadah@mcw.edu. pancreatitis and comorbid AF using the NIS. Patients were filtered using ICD-10-CM codes.

We identified all adult patients older than 18 years who were admitted with acute pancreatitis with and without concomitant primary or secondary AF in 2016 and 2017. Our institution does not require the attainment of ethical approval for NIS database studies. We excluded any patients who were hospitalized with missing demographics (eg, age, sex, admission or discharge diagnosis, and mortality data). We used NIS variables to identify patients' age, sex, race, county location, county income, number of hospital beds, and alcohol abuse. Race was divided into two categories (white and nonwhite).

\section{Outcomes}

Our objectives were to assess the disease severity and inpatient outcomes in patients admitted with a principal diagnosis of acute pancreatitis with and without concurrent AF. The primary outcomes analyzed were mortality of all patients admitted with a principal diagnosis of acute pancreatitis with and without concurrent AF. Secondary outcomes associated with acute pancreatitis and AF were heart block, cardiogenic shock, cardiac arrest, sepsis, hemorrhage, stroke, heart failure, acute coronary syndrome, pericardial complications, cardiac electronic implantable devices, valvular complications, deep venous thrombosis and pulmonary embolism, acute kidney injury, acute kidney injury requiring hemodialysis, and length and cost of hospital stay.

\section{Statistical analysis}

We used survey analyses for stratifying and clustering encounters for all continuous and categorical variables. The Stata software program (StataCorp LLC, College Station, TX, USA) was used to perform statistical analyses. We used the chi-squared test or analysis of variance to identify differences in categorical variables and the two-sample t-test for the analysis of continuous variables. A logistic regression model was used to calculate the odds ratio (OR) for outcomes between the two study groups. This was followed by the conduct of multivariate analyses to account for any confounders in the form of comorbidities between the two groups. A p-value of less than 0.05 was considered to be statistically significant. We audited the analyses using the checklist provided by the NIS to assess and ensure that the data analyses were compliant with the rules recommended by the NIS. ${ }^{13}$ Multivariate analysis was performed and adjusted for statistically significant baseline characteristics (eg, age, sex, race, Charlson Comorbidity Index, hospital bed size, primary payer, median household income, hospital region, dyslipidemia, old myocardial infarction, old percutaneous intervention, old coronary artery bypass grafting, history of pacemaker implantation, chronic obstructive pulmonary disease, carotid artery disease, history of stroke, hypertension, peripheral arterial disease, diabetes mellitus types 1 and 2, obesity, chronic kidney disease, liver disease, and history of smoking). 
Table 1: ICD-10-CM and Procedure Coding System

\begin{tabular}{|c|c|}
\hline Variable & ICD 10 Codes \\
\hline $\begin{array}{l}\text { Acute } \\
\text { pancreatitis }\end{array}$ & $\begin{array}{l}\text { K85.0, K85.00, K85.01, K85.02, K85.1, } \\
\text { K85.10, K85.11, K85.12, K85.2, K85.20, } \\
\text { K85.21, K85.22, K85.3, K85.30, K85.31, } \\
\text { K85.32, K85.8, K85.80, K85.81, K85.82, } \\
\text { K85.9, K85.90, K85.91, K85.92 }\end{array}$ \\
\hline $\begin{array}{l}\text { Atrial fibrillation/ } \\
\text { flutter }\end{array}$ & $\begin{array}{l}148,148.0,148.1,148.11,148.19,148.2,148.20 \\
148.21,148.3,148.4,148.9,148.91,148.92\end{array}$ \\
\hline $\begin{array}{l}\text { Bleeding } \\
\text { complications }\end{array}$ & $\begin{array}{l}\text { K29.01, K62.5, K31.811, K57, K29, K25, K26, } \\
\text { K27, K28, 185.01, N93 }\end{array}$ \\
\hline Heart failure & 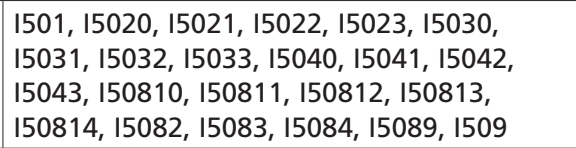 \\
\hline Heart block & $\begin{array}{l}1445,1452,14430,1441,1447,1455,1444,1442, \\
1440,14439,14460,14469,1450,14510,14519, \\
1453,1454\end{array}$ \\
\hline $\begin{array}{l}\text { Valvular heart } \\
\text { diseases }\end{array}$ & $\begin{array}{l}1340,1341,1342,1348,1349,1350,1351,1352, \\
1358,1359,1360,1361,1362,1368,1369,1370 \\
1371,1372,1378,1379\end{array}$ \\
\hline $\begin{array}{l}\text { Cardiogenic } \\
\text { shock }\end{array}$ & R57.0 \\
\hline Stroke & $\begin{array}{l}169.30,169.31,169.320-169.323,169.328, \\
169.331-169.334,169.339,169.341-169.344, \\
169.349,169.351-169.354,169.359 \\
169.361-169.364,169.369,169.390-169.393 \\
169.398,163,169,16010,16011,16012,1602, \\
16030,16031,16032,1604,16050,16051 \\
16052,1606,1607,1608,1609,1610,1611,1612 \\
1613,1614,1615,1616,1618,1619,16200 \\
16201,16202,16203,1621,1629,160\end{array}$ \\
\hline $\begin{array}{l}\text { In-hospital } \\
\text { cardiac } \\
\text { implantable } \\
\text { electronic device } \\
\text { placement }\end{array}$ & $\begin{array}{l}\text { 0JH604Z, 0JH634Z, 0JH804Z, 0JH834Z, } \\
\text { 0JH605Z, 0JH635Z, 0JH805Z, 0JH835Z } \\
\text { 0JH606Z, 0JH636Z, 0JH806Z, 0JH836Z } \\
\text { 0JH60PZ, 0JH63PZ, 0JH80PZ, 0JH83PZ } \\
\text { 0JH608Z, 0JH638Z, 0JH808Z, 0JH838Z }\end{array}$ \\
\hline Cardiac arrest & $146,1468,1469,1462$ \\
\hline $\begin{array}{l}\text { In-hospital } \\
\text { resuscitation }\end{array}$ & $5 A 2204 Z$ \\
\hline $\begin{array}{l}\text { Acute coronary } \\
\text { syndrome }\end{array}$ & $\begin{array}{l}\text { I2101, I2102, I2109, I2111, I2119, I2121, } \\
\text { I2129, I213, I214, I219, I21A9, I220, I221, } \\
\text { I222, I228, I229 }\end{array}$ \\
\hline $\begin{array}{l}\text { Acute kidney } \\
\text { injury }\end{array}$ & N170, N171, N172, N178, N179 \\
\hline Hemodialysis & 5A1D70Z, 5A1D80Z, 5A1D90Z \\
\hline $\begin{array}{l}\text { Postprocedural } \\
\text { pneumothorax }\end{array}$ & J95.811 \\
\hline $\begin{array}{l}\text { Postoperative } \\
\text { respiratory } \\
\text { failure }\end{array}$ & J95.821 \\
\hline $\begin{array}{l}\text { Other iatrogenic } \\
\text { respiratory } \\
\text { complications }\end{array}$ & $\begin{array}{l}\text { Ventilator-associated pneumonia (J95.851) } \\
\text { Postprocedural aspiration pneumonia } \\
\text { (J95.89) } \\
\text { Other respiratory complications (J95.859, } \\
\text { J95.88, J95.89) }\end{array}$ \\
\hline Sepsis & $\begin{array}{l}\text { A40.0, A40.1, A40.8, A40.9, A40.3, A41.89, } \\
\text { A41.4, A41.59, A41.81, A41.1, A41.3, A41.9, } \\
\text { A41.01, R65.21, R65.20, R65.10, R65.11 }\end{array}$ \\
\hline
\end{tabular}

Table 2: Baseline Characteristics of Acute Pancreatitis Hospitalizations with and without AF $(n=575,230)$

\begin{tabular}{|c|c|c|c|}
\hline & $\begin{array}{c}\text { Without AF } \\
(n=542,440)\end{array}$ & $\begin{array}{c}\text { With AF } \\
(n=32,790)\end{array}$ & p-value \\
\hline Mean age, years & 50.78 & 70.47 & $<0.0001$ \\
\hline Female sex & $47.18 \%$ & $42.05 \%$ & $<0.0001$ \\
\hline \multicolumn{3}{|l|}{ Race } & $<0.0001$ \\
\hline White & $63.49 \%$ & $79.78 \%$ & $<0.0001$ \\
\hline Black & $17.53 \%$ & $9.76 \%$ & $<0.0001$ \\
\hline Hispanic & $13.12 \%$ & $6.15 \%$ & $<0.0001$ \\
\hline Asians & $2.05 \%$ & $1.94 \%$ & 0.003 \\
\hline Native Americans & $0.89 \%$ & $0.6 \%$ & $<0.0001$ \\
\hline Others & $2.92 \%$ & $1.77 \%$ & $<0.0001$ \\
\hline \multicolumn{3}{|c|}{ Charlson Comorbidity Index } & $<0.0001$ \\
\hline 0 & $42.15 \%$ & $19.17 \%$ & \\
\hline 1 & $30.22 \%$ & $23.35 \%$ & \\
\hline 2 & $13.45 \%$ & $19.64 \%$ & \\
\hline$\geq 3$ & $14.18 \%$ & $37.85 \%$ & \\
\hline \multicolumn{3}{|l|}{ Hospital bed size } & $<0.0001$ \\
\hline Small & $23.43 \%$ & $21.53 \%$ & \\
\hline Medium & $30.83 \%$ & $29.46 \%$ & \\
\hline Large & $45.74 \%$ & $49.01 \%$ & \\
\hline \multicolumn{3}{|c|}{ Hospital teaching status } & 0.1066 \\
\hline Nonteaching & $40.10 \%$ & $39.02 \%$ & \\
\hline Teaching & $59.90 \%$ & $60.98 \%$ & \\
\hline \multicolumn{3}{|l|}{ Hospital location } & 0.5569 \\
\hline Rural & $12.18 \%$ & $11.92 \%$ & \\
\hline Urban & $87.82 \%$ & $88.08 \%$ & \\
\hline \multicolumn{3}{|c|}{ Expected primary payer } & $<0.0001$ \\
\hline Medicare & $29.63 \%$ & $72.10 \%$ & \\
\hline Medicaid & $26.28 \%$ & $9.0 \%$ & \\
\hline Private & $34.36 \%$ & $16.53 \%$ & \\
\hline Self-pay & $9.73 \%$ & $2.36 \%$ & \\
\hline \multicolumn{3}{|c|}{ Median household income (quartile) } & $<0.0001$ \\
\hline $1^{\text {st }}\left(0-25^{\text {th }}\right)$ & $33.26 \%$ & $29.16 \%$ & \\
\hline $2^{\text {nd }}\left(26\right.$ th- $\left.-50^{\text {th }}\right)$ & $26.67 \%$ & $27.29 \%$ & \\
\hline $3^{\text {rd }}\left(51 \mathrm{st}-75^{\text {th }}\right)$ & $23.12 \%$ & $24 \%$ & \\
\hline $4^{\text {th }}\left(76\right.$ th- $\left.-100^{\text {th }}\right)$ & $16.95 \%$ & $19.56 \%$ & \\
\hline \multicolumn{3}{|l|}{ Hospital region } & 0.0061 \\
\hline Northeast & $16.73 \%$ & $18.18 \%$ & \\
\hline Midwest & $22.55 \%$ & $23.38 \%$ & \\
\hline South & $41.03 \%$ & $39.45 \%$ & \\
\hline West & $19.69 \%$ & $19.00 \%$ & \\
\hline Dyslipidemia & $31.49 \%$ & $49.85 \%$ & $<0.0001$ \\
\hline Old MI & $3.26 \%$ & $9.94 \%$ & $<0.0001$ \\
\hline Old PCI & $0.33 \%$ & $1.14 \%$ & $<0.0001$ \\
\hline Old CABG & $2.08 \%$ & $9.18 \%$ & $<0.0001$ \\
\hline Old pacemaker & $0.71 \%$ & $8.75 \%$ & $<0.0001$ \\
\hline COPD & $8.90 \%$ & $20.62 \%$ & $<0.0001$ \\
\hline Carotid artery disease & $0.17 \%$ & $0.91 \%$ & $<0.0001$ \\
\hline HTN & $46.56 \%$ & $51.45 \%$ & $<0.0001$ \\
\hline $\begin{array}{l}\text { Peripheral vessel } \\
\text { disease }\end{array}$ & $1.31 \%$ & $4.82 \%$ & $<0.0001$ \\
\hline Hypothyroidism & $8.32 \%$ & $16.74 \%$ & $<0.0001$ \\
\hline DM types 1 and 2 & $25.93 \%$ & $34.35 \%$ & $<0.0001$ \\
\hline
\end{tabular}


Table 2: (continued)

\begin{tabular}{|l|l|l|l|}
\hline & $\begin{array}{c}\text { Without AF } \\
(\mathbf{n}=\mathbf{5 4 2 , 4 4 0 )}\end{array}$ & $\begin{array}{c}\text { With AF } \\
(\mathbf{n}=\mathbf{3 2 , 7 9 0 )}\end{array}$ & p-value \\
\hline Obesity & $15.85 \%$ & $18.15 \%$ & $<0.0001$ \\
\hline CKD & $8.03 \%$ & $24.53 \%$ & $<0.0001$ \\
\hline Liver disease & $19.10 \%$ & $14.62 \%$ & $<0.0001$ \\
\hline Electrolyte imbalance & $31.92 \%$ & $34.55 \%$ & $<0.0001$ \\
\hline $\begin{array}{l}\text { Maintenance } \\
\text { hemodialysis }\end{array}$ & $1.57 \%$ & $3.05 \%$ & $<0.0001$ \\
\hline O $_{2}$ dependence & $0.79 \%$ & $3.03 \%$ & $<0.0001$ \\
\hline Smoking & $19.14 \%$ & $27.08 \%$ & $<0.0001$ \\
\hline Anemia & $16.90 \%$ & $24.87 \%$ & $<0.0001$ \\
\hline Taking anticoagulants & $2.07 \%$ & $33.36 \%$ & $<0.0001$ \\
\hline CAD & $8.91 \%$ & $32.02 \%$ & $<0.0001$ \\
\hline
\end{tabular}

AF: atrial fibrillation/flutter; CABG: coronary artery bypass graft; CAD: coronary artery disease; CKD: chronic kidney disease; COPD: chronic obstructive pulmonary disease; DM: diabetes mellitus; HTN: hypertension; median household income: median household income for patient's zip code; MI: myocardial infarction; $\mathrm{O}_{2}$ : oxygen; $\mathrm{PCl}$ : percutaneous coronary intervention.

\section{Results}

We identified a total of 71 million hospitalizations in 2016 and 2017. Of these, we further identified 575,230 patients with a principal diagnosis of acute pancreatitis based on the ICD-10 codes mentioned in Table 1. Of these, 542,440 patients did not have concurrent AF and 32,790 patients had concurrent AF. Thus, our final sample included two study groups: patients with acute pancreatitis only and patients with acute pancreatitis and AF. Table 2 shows the background characteristics by study group; patients with acute pancreatitis and AF were significantly older (70.47 versus 50.78 years; $p<0.0001)$, more often were male $(42 \%$ versus $47 \%$; $\mathrm{p}<0.001)$, more frequently were white $(79 \%$ versus 63\%; $\mathrm{p}<0.0001$ ), and had Charlson Comorbidity Index scores of two or three or more points $(p<0.0001)$ than those participants in the group with acute pancreatitis only. Patients with acute pancreatitis and AF had higher baseline comorbidity burdens such as dyslipidemia, old myocardial infarction, percutaneous coronary intervention and coronary artery bypass graft, coronary artery disease, chronic obstructive pulmonary disease, peripheral arterial disease, hypertension, diabetes mellitus types 1 and 2, obesity, chronic kidney disease, liver disease, maintenance hemodialysis, oxygen dependence, and anemia.

Table 3 summarizes the results of the logistic regression analyses of the adjusted ORs used to control for the variables in Table 2. Patients with acute pancreatitis and AF demonstrated twofold to threefold greater mortality [adjusted OR: 2.59; 95\% confidence interval (CI): 2.04-3.28]. Patients with acute pancreatitis and AF also

Table 3: Clinical Outcomes of Acute Pancreatitis with and without AF

\begin{tabular}{|c|c|c|c|c|}
\hline & $\begin{array}{c}\text { Acute Pancreatitis } \\
\text { Without AF } \\
(n=32,790), \%\end{array}$ & $\begin{array}{c}\text { Acute Pancreatitis } \\
\text { and AF } \\
(n=542,440), \%\end{array}$ & Adjusted OR (95\% Cl) & p-value \\
\hline \multicolumn{5}{|l|}{ Primary outcome } \\
\hline In-hospital mortality & 0.46 & 2.76 & $2.59(2.04-3.28)$ & $<0.0001 *$ \\
\hline \multicolumn{5}{|l|}{ Secondary outcomes } \\
\hline Heart block & 0.81 & 4.09 & $1.86(1.55-2.24)$ & $<0.0001 *$ \\
\hline Cardiogenic shock & 0.04 & 0.32 & $3.14(1.39-7.09)$ & $0.006^{*}$ \\
\hline Cardiac arrest & 0.19 & 0.81 & $2.68(1.76-4.09)$ & $<0.0001 *$ \\
\hline Pericardial complications & 0.15 & 0.76 & $3.38(2.21-5.17)$ & $<0.0001 *$ \\
\hline Valvular complications & 0.87 & 5.31 & $1.76(1.49-2.08)$ & $<0.0001 *$ \\
\hline Bleeding complications & 11.51 & 13.40 & $0.92(0.84-1.01)$ & 0.073 \\
\hline ACS & 0.31 & 1.52 & $1.61(1.17-2.21)$ & $0.003^{*}$ \\
\hline Stroke & 0.02 & 0.15 & $3.94(1.42-10.93)$ & $0.009 *$ \\
\hline $\mathrm{CHF}$ & 4.17 & 28.77 & $3.16(2.87-3.49)$ & $<0.0001$ \\
\hline CIED & 0.01 & 0.20 & $9.52(3.79-23.94)$ & $<0.0001 *$ \\
\hline Sepsis & 1.19 & 4.06 & $2.49(2.06-3.01)$ & $<0.0001 *$ \\
\hline AKI & 10.1 & 23.83 & $1.42(1.30-1.55)$ & $<0.0001$ \\
\hline $\mathrm{AKI}$ requiring $\mathrm{HD}$ & 0.04 & 0.21 & $2.55(1.17-5.60)$ & $0.019 *$ \\
\hline DVT/PE & 1.14 & 2.27 & $0.88(0.66-1.16)$ & 0.350 \\
\hline \multicolumn{5}{|l|}{ Adjusted mean difference } \\
\hline Mean LOS, days & 4.22 & 6.13 & $1.28(1.08-1.48)$ & $<0.0001 *$ \\
\hline Mean total charge, USD & 36,980 & 59,631 & $17,489(14,349-20,628)$ & $<0.0001 *$ \\
\hline
\end{tabular}

ACS: acute coronary syndrome; AF: atrial fibrillation/flutter; AKI: acute kidney injury;

CHF: congestive heart failure; $\mathrm{Cl}$ : confidence interval; CIED: cardiovascular implantable electronic device; DVT: deep venous thrombus; HD: hemodialysis; LOS: length of hospital stay; OD: odds ratio; PE: pulmonary embolus; USD: United States dollars.

*Statistically significant after adjusting for the variables in Table $\mathbf{2}$. 
had higher odds of heart block (adjusted OR: 1.86; 95\% CI: 1.55-2.24), cardiac arrest (adjusted OR: 2.68; 95\% CI: 1.76-4.09), cardiogenic shock (adjusted OR: 3.14; 95\% CI: 1.39-7.09), pericardial complications (adjusted OR: 3.38; 95\% CI: 2.21-5.17), valvular complications (adjusted OR: 1.76; 95\% CI: 1.49-2.08), acute coronary syndrome (adjusted OR: 1.61; 95\% CI: 1.17-2.21), cardiac implantable electronic devices (adjusted OR: 9.52; 95\% CI: 3.79-23.94), stroke (adjusted OR: 3.94; 95\% CI: 1.42 10.93), congestive heart failure (adjusted OR: 3.16 ; 95\% CI: 2.87-3.49), acute kidney injury (adjusted OR: 1.42; 95\% CI: 1.30-1.55), acute kidney injury requiring hemodialysis (adjusted OR: 2.55; 95\% CI: 1.17-5.60), sepsis (adjusted OR: 2.49; 95\% CI: 2.06-3.01), increased length of hospital stay (adjusted OR: 1.28; 95\% CI: 1.08-1.48), and greater cost of hospital stay (adjusted OR: 17,489; 95\% CI: $14,349-20,628)$.

\section{Discussion}

The principal findings of this study were the following: there was a significantly increased mortality rate among patients with acute pancreatitis and concurrent $\mathrm{AF}$, the cardiovascular morbidity burden was significantly higher in acute pancreatitis and AF, patients with acute pancreatitis and AF were at significantly increased risk of stroke, concurrent AF increases the risk of renal failure in patients, and age and male sex are important and significant predictors of outcomes in patients with acute pancreatitis and $\mathrm{AF}$.

Mortality in acute pancreatitis depends on the disease severity and varies from $2 \%$ in mild cases to $46 \%$ in the most severe context. ${ }^{14}$ This is thought to result from MODS. ${ }^{15}$ Similarly, AF is known to cause a fourfold increased mortality risk relative to that in the general population. ${ }^{16} \mathrm{AF}$ is an independent risk factor for mortality after adjusting for cardiovascular comorbidities. ${ }^{17}$ We report a statistically significant twofold to threefold increase in mortality with an adjusted OR of 2.59 in patients with acute pancreatitis and concurrent AF. This trend is thought to be compounded by an increase in other adverse outcomes such as acute coronary syndrome, congestive heart failure, cardiac arrest, heart blocks, cardiogenic shock, stroke, and sepsis. Persistent organ dysfunction can result in a mortality rate as high as $30 \%{ }^{18}$

The outcomes of acute pancreatitis depend on its severity, ranging from self-limiting episodes to multiorgan failure leading to mortality. ${ }^{19}$ This is related to the degree of insult to the pancreas, which can be mild, in the form of interstitial edematous pancreatitis, or more severe, such as necrotizing pancreatitis, which warrants surgical intervention. ${ }^{20,21}$ In one study, alcohol was considered as a major triggering factor, followed by gallstones, iatrogenic factors, and hyperlipidemia. In the same study, pulmonary, cardiovascular, renal, hematologic (disseminated intravascular coagulation), and hepatic complications were primarily reported as elements of MODS, whereas cardiac failure was the major cause of mortality in both the in-patient setting and during follow-up. ${ }^{22}$ In another retrospective study, the prevalence rates of cardiovascular comorbidities, including heart failure, coronary artery disease, and $\mathrm{AF}$, were higher among patients with chronic pancreatitis. $^{23}$

Acute pancreatitis can manifest as SIRS, which is considered to be an important prognostic factor in determining the morbidity and mortality rates. ${ }^{24,25}$ SIRS triggers the release of inflammatory cytokines (tumor necrosis factor- $\alpha$, interleukin- 6 , and C-reactive protein), leading to multiorgan failure, which, in turn, places increased stress on the heart and triggers malignant arrhythmias. ${ }^{26} \mathrm{AF}$ is considered one of the most commonly observed arrhythmias in critically ill and hospitalized patients. ${ }^{27}$ The possible mechanisms may include superimposed effects of fluid resuscitation, which is the mainstay of management to control inflammation, and hemodynamic support, leading to volume overload in patients with cardiovascular-compromised states (eg, heart failure, ischemic heart disease), resulting in atrial myocardial stretch and triggering AF. Another possible mechanism could be an imbalance between the sympathetic and parasympathetic nervous systems, with changes in hemodynamics triggering alterations in heart rate variability, resulting in atrial and ventricular arrhythmias. ${ }^{27-30}$

AF is considered an important prognostic factor in determining morbidity and mortality in both critical and noncritical patients due to the risk of thromboembolism and stroke, impairment in the quality of life, congestive heart failure, pulmonary/renal complications, and increased health-care costs. ${ }^{31-35}$ Severe forms of acute pancreatitis can result in sepsis and septic shock, which, if they cause new-onset AF, are known to culminate in adverse outcomes such as a prolonged and increased need for mechanical ventilation, longer hospital/intensive care unit length of stay, and increased mortality (69\% versus $40 \%$ ) as compared with among patients without $\mathrm{AF}^{33}$ The prevalence of sepsis in the group with acute pancreatitis and AF was $4.06 \%$ as compared with $1.19 \%$ in the group with acute pancreatitis only, which could very well explain the possibility of new-onset AF.

The purpose of this study was to show and quantify how concurrent AF worsens the disease burden and mortality in patients admitted in an inpatient setting for acute pancreatitis. We have observed an increased risk of cardiovascular, neurologic, and renal complications in patients with acute pancreatitis and concurrent AF as compared with among patients with acute pancreatitis only. These complications lead to additional interventions that contribute to the increased length of stay. The mean difference in the length of stay between the two groups in our study was approximately two days.

\section{Limitations}

The inherent nature of a cross-sectional study did not allow us to calculate the incidence and rate ratios. The use of the Healthcare Cost and Utilization project database 
also has limitations of its own-for example, with respect to the selected group of patients included in the database. We could not stratify acute pancreatitis according to severity based on the gathered data, which can have prognostic implications. Similarly, it could not be determined whether the patients had paroxysmal or persistent AF. Meanwhile, the NIS database is primarily compiled based on ICD codes, which represent "claims data" for reimbursement purposes and for summarizing clinical presentations in retrospect; it does not give us information regarding the clinical presentation (ie, "clinical data"). Further studies are required to incorporate both claims and clinical data to ensure a deeper understanding of outcomes in patients admitted for acute pancreatitis and to assess its outcomes while influenced by the presence of concurrent AF. The other limitation of multivariate regression analysis is that it cannot determine causation; only the association between predictors and outcomes can be revealed. However, similar to propensity matching, multivariate regression analysis can also be used to adjust for confounders and differences in baseline characteristics between two cohorts.

Separately, this study has some strengths if carefully analyzed. The large sample size, which was made possible with the use of the NIS database, increases the precision of the study results and also allowed us to gather information about other variables and comorbidities, which have provided meaningful results. The increased mortality rate and significant trend toward other outcomes in the group of patients with pancreatitis and AF can serve as a platform for further research. Given the increased prevalence of these two comorbidities worldwide, new ideas and management strategies should be formulated, which can alter the future of clinical practice for good.

\section{Conclusion}

The presence of concurrent AF in patients with acute pancreatitis predicts higher mortality rates and adverse clinical outcomes. Further studies in the future can help us to understand the underlying pathogenesis of these outcomes and also help with devising strategies to improve outcomes in such a cohort of patients.

\section{References}

1. Tenner S, Sica GR, Hughes MI, Feng S, Zinner M, Banks PA. Relationship of necrosis to organ failure in severe acute pancreatitis. Gastroenterology. 1997;113(3):899-903.

2. Wilson C, Imrie CW. Deaths from acute pancreatitis: why do we miss the diagnosis so frequently? Int J Pancreatol. 1988;3(4):273-281.

3. Agarwal N, Pitchumoni CS. Acute pancreatitis: a multisystem disease. Gastroenterologist. 1993;1(2):115-128.

4. Saulea A, Costin S, Rotari V. Heart ultrastructure in experimental acute pancreatitis. Rom J Physiol. 1997;34(1-4):35-44.

5. Kanaian AS, Permiakov NK, Khandanian RK, Gevorkian GA. Combined pathology of the pancreas and myocardium in myocardial infarction and acute destructive pancreatitis. Arkh Patol. 1996;58(5):56-61.

6. Banks PA. Epidemiology, natural history, and predictors of disease outcome in acute and chronic pancreatitis. Gastrointest Endosc. 2002;56(6):S226-S230.

7. Rau BM, Bothe A, Kron M, Beger HG. Role of early multisystem organ failure as major risk factor for pancreatic infections and death in severe acute pancreatitis. Clin Gastroenterol Hepatol. 2006;4(8):1053-1061.

8. Peery AF, Dellon ES, Lund J, Crockett SD, McGowan $\mathrm{CE}$, Bulsiewicz WJ, et al. Burden of gastrointestinal disease in the United States: 2012 update. Gastroenterology. 2012;143(5):1179-1187.

9. Working Group IAP/APA Acute Pancreatitis Guidelines. IAP / APA evidence-based guidelines for the management of acute pancreatitis. Pancreatology. 2013;13(4):e1-e5.

10. Banks PA, Freeman ML. Practice Parameters Committee of the American College of G. Practice guidelines in acute pancreatitis. Am J Gastroenterol. 2006;101(10):2379-2400.

11. Gullo L, Labriola E, Di SB, Priori P, Iannacci P, Pezzilli R. Acute pancreatitis associated with paroxysmal atrial fibrillation. A case report. Panminerva Med. 1988;30(2):111-113.

12. Voruganti DC, Shantha G, Dugyala S, Pothineni NVK, Mallick DC, Deshmukh A, et al. Temporal trends and factors associated with increased mortality among atrial fibrillation weekend hospitalizations: an insight from National Inpatient Sample 2005-2014. BMC Res Notes. 2019;12(1):398-398.

13. Healthcare Cost and Utilization Project. Checklist for working with the NIS. Available at: https://www.hcup-us.ahrq. gov/db/nation/nis/nischecklist.jsp. Accessed July 24, 2020.

14. Popa CC, Badiu DC, Rusu OC, Grigorean VT, Neagu SI, Strugaru CR. Mortality prognostic factors in acute pancreatitis. J Med Life. 2016;9(4):413-418.

15. Gloor B, Müller CA, Worni M, Martignoni ME, Uhl W, Büchler MW. Late mortality in patients with severe acute pancreatitis. Br J Surg. 2001;88(7):975-979.

16. Lee E, Choi E-K, Han K-D, Lee HJ, Choe W-S, Lee S-R, et al. Mortality and causes of death in patients with atrial fibrillation: a nationwide population-based study. PLoS One. 2018;13(12):e0209687.

17. Benjamin EJ, Wolf PA, D'Agostino RB, Silbershatz $\mathrm{H}$, Kannel WB, Levy D. Impact of atrial fibrillation on the risk of death: the Framingham Heart Study. Circulation. 1998;98(10):946-952.

18. Yadav D, Lowenfels AB. The epidemiology of pancreatitis and pancreatic cancer. Gastroenterology. 2013;144(6):1252-1261.

19. Allardyce DB. Incidence of necrotizing pancreatitis and factors related to mortality. Am J Surg. 1987;154(3):295-299.

20. Buchler M, Hauke A, Malfertheimer P. Follow-up after acute pancreatitis: morphology and function. In: Beger HB, Büchler M, eds. Acute Pancreatitis. Heidelberg: Springer; 1987:367-374.

21. Svensson JO, Norback B, Bokey EL, Edlund Y. Changing pattern in aetiology of pancreatitis in an urban Swedish area. Br J Surg. 1979;66(3):159-161.

22. Appelros S, Lindgren S, Borgström A. Short and long term outcome of severe acute pancreatitis. Eur J Surg. 2001;167(4):281-286.

23. Wong TS, Liao KF, Lin CM, Lin CL, Chen WC, Lai SW. Chronic pancreatitis correlates with increased risk of cerebrovascular disease: a retrospective population-based cohort study in Taiwan. Medicine (Baltimore). 2016;95(15):e3266.

24. Krishnagopalan S, Kumar A, Parrillo JE, Kumar A. Myocardial dysfunction in the patient with sepsis. Curr Opin Crit Care. 2002;8(5):376-88. 
25. Rangel-Faustro MS. The epidemiology of bacterial sepsis. Infect Dis Clin North Am. 1999;13(2):299-311.

26. Engelmann MD, Svendsen JH. Inflammation in the genesis and perpetuation of atrial fibrillation. Eur Heart J. 2005;26(20):2083-2092.

27. Aldhoon B, Melenovský V, Peichl P, Kautzner J. New insights into mechanisms of atrial fibrillation. Physiol Res. 2010;59(1):1-12.

28. Maisel WH, Rawn JD, Stevenson WG. Atrial fibrillation after cardiac surgery. Ann Intern Med. 2001;135(12):1061-1073.

29. Kühlkamp V, Schirdewan A, Stangl K, Homberg M, Ploch $\mathrm{M}$, Beck OA. Use of metoprolol CR/XL to maintain sinus rhythm after conversion from persistent atrial fibrillation: a randomized, double-blind, placebo-controlled study. J Am Coll Cardiol. 2000;36(1):139-146.

30. Werdan K, Schmidt H, Ebelt H, Zorn-Pauly K, Koidl B, Hoke RS, et al. Impaired regulation of cardiac function in sepsis, SIRS, and MODS. Can J Physiol Pharmacol. 2009;87(4):266-274.
31. Camm AJ, Kirchhof P, Lip GY, Schotten U, Savelieva I, Ernst $S$, et al. Guidelines for the management of atrial fibrillation: the Task Force for the Management of Atrial Fibrillation of the European Society of Cardiology (ESC). Europace. 2010;12(10):1360-1420.

32. Lip GY, Tse HF. Management of atrial fibrillation. Lancet. 2007;370(9587):604-618.

33. Christian SA, Schorr C, Ferchau L, Jarbrink ME, Parrillo JE, Gerber DR. Clinical characteristics and outcomes of septic patients with new-onset atrial fibrillation. J Crit Care. 2008;23(4):532-536.

34. Meierhenrich R, Steinhilber E, Eggermann C, Weiss M, Voglic S, Bögelein D, et al. Incidence and prognostic impact of new-onset atrial fibrillation in patients with septic shock: a prospective observational study. Crit Care. 2010;14(3):R108.

35. Lai S-W, Lin C-L, Liao K-F. Atrial fibrillation associated with acute pancreatitis: a retrospective cohort study in Taiwan. $J$ Hepatobiliary Pancreat Sci. 2016;23(4):242-247. 